\title{
Moral/conventional transgression distinction and psychopathy in conduct disordered adolescent offenders
}

\author{
Mairead C. Dolan ${ }^{*}$, Rachael S. Fullam \\ Centre for Forensic Behavioural Science, Monash University, Victorian Institute of Forensic Mental Health, Melbourne, Australia
}

\section{A R T I C L E I N F O}

\section{Article history:}

Received 12 April 2010

Received in revised form 10 August 2010

Accepted 11 August 2010

\section{Keywords:}

Psychopathy

Adolescence

Moral development

Emotion

\begin{abstract}
A B S T R A C T
To date there are no studies examining the ability to make a moral/conventional transgression distinction in adolescent offenders with psychopathic traits. Based on the Psychopathy Checklist: Youth Version, we compared males with high (HP, $n=45$ ), medium (MP, $n=31$ ) and low psychopathy scores (LP, $n=39$ ) on the moral convention distinction task. Under normal rule conditions the psychopathy groups did not differ in their ability to make a moral/conventional distinction. The HP group tended to view both transgression types as more permissible and conventional transgressions as less serious, than the LP group. Under modified rule conditions, the HP group exhibited reduced moral/conventional distinction scores compared to the MP group. The findings only partially replicate findings from previous M/C studies in children and adults with psychopathic traits. The work fits with more recent reports suggesting that psychopathy is not strongly associated with marked difficulties in cognitive theory of mind, perspective taking and moral judgements. Future studies should focus on the affective aspects of moral reasoning in offender samples.
\end{abstract}

(c) 2010 Elsevier Ltd. All rights reserved.

\section{Introduction}

In recent years there has been growing interest in moral development in adolescence (Hart \& Carlo, 2005) and its relevance to psychopathic traits (Maxwell \& Le Sage, 2009). Studies suggest that juvenile delinquents have impairments in moral judgement compared to non-delinquent peers (Gregg, Gibbs, \& Basinger, 1994; Nelson, Smith, \& Dodd, 1990). Psychopathic traits have been found to be associated with emotional deficits and difficulties in behavioural inhibition, which may account for delinquent morally inappropriate behaviours (Blair, 2007). Blair (1995) developed the Violence Inhibition Mechanism (VIM) and later the Integrated Emotional System (IES; Blair, 2005) neurobehavioral models to explain psychopathic behaviour from an empathy perspective. The IES suggests that deficits in the key brain structures/circuits involved in emotional information processing result in impaired moral socialisation (Blair, 2005). According to the IES, seeing distress in others is aversive, and results in increased autonomic activity and activation of the brain's threat (prefrontal-limbic) response system (Blair, 2005). IES dysfunction may account, at least in part, for the observed psychopathy-related deficits in emotional information processing (Blair, 2007), and the ability to make a

\footnotetext{
* Corresponding author. Address: Centre for Forensic Behavioural Science, The Paul Mullen Centre, 505 Hoddle Street, Clifton Hill, Vic 3068, Australia. Tel.: +61 3 9947 2500; fax: +61 399472599.

E-mail address: Mairead.Dolan@forensicare.vic.gov.au (M.C. Dolan).
}

moral/conventional $(\mathrm{M} / \mathrm{C})$ transgression distinction. Research on the $\mathrm{M} / \mathrm{C}$ distinction task suggests that moral transgressions are generally victim based and reflect others' welfare. By contrast, conventional transgressions are seen as non-victim based and refer to the understanding of appropriate social behaviour. Moral and conventional transgressions are distinguished according to two classes of criterion judgement. The first relates to judgements made under normal rule conditions (e.g. the permissibility and seriousness judgements). The second refers to judgements made under modified rule conditions (e.g. the teacher authority judgement i.e. authority jurisdiction). In normally developing individuals moral transgressions are judged to be more serious than conventional transgressions, and they are less likely to be seen as acceptable even when an authority says the act is permissible (Nucci, 1981). This $\mathrm{M} / \mathrm{C}$ distinction is normally in place from the age of 3 years (Smetana, 1995). As moral development is thought to be developmentally delayed in delinquents (Gregg et al., 1994), the M/C distinction task may be a useful means of testing this hypothesis across the lifespan.

There are now a number of studies investigating moral and empathy deficits in adult psychopathy (Blair, 2007; Glenn, Raine, \& Schug, 2009) from an affective empathy/ emotional information processing perspective. There are, however, few studies looking at the cognitive developmental ability to distinguish between moral and conventional transgressions in antisocial and psychopathic samples (Blair, 1995, 1997; Blair, Monson, \& Frederickson, 2001; Fisher \& Blair, 1998; Nucci \& Herman, 1982). In line with IES 
predictions, Blair (1995) reported that adult psychopaths treated conventional transgressions like moral transgressions and were less likely to refer to victim welfare. In children with psychopathic traits, Blair (1997) and Blair et al. (2001) noted that they did not differ from those without these traits in terms of the permissibility and seriousness of moral and conventional transgressions under normal rules, but high psychopathy scorers showed less of a $\mathrm{M} / \mathrm{C}$ distinction than the controls in the modified rule condition. Blair (1997) initially found no psychopathy-related group differences in the number of references to victim welfare in a sample of children, but subsequently reported reduced reference to victim welfare under modified rule conditions in a larger sample of children with psychopathic traits (Blair et al., 2001). We investigated the relationship between psychopathy and the ability to make a $\mathrm{M} / \mathrm{C}$ distinction in adolescent offenders.

Based on Blair's work, we hypothesized that adolescents with high psychopathy scores would show impairments in a range of domains in the $\mathrm{M} / \mathrm{C}$ distinction task most notably under modified rule conditions, but that the findings from his data on children may be only partially supported as performance on the $\mathrm{M} / \mathrm{C}$ task is developmentally influenced. Given the emphasis of the IES model of psychopathy on affective deficits, we also hypothesised that impaired performance on the moral/convention distinction task would be most strongly related to the affective facet of psychopathy.

\section{Method}

\subsection{Participants}

Participants were 115 male adolescents who were in secure care or in young offender's institutions in the North West Region of England, and who met criteria for DSM-IV conduct disorder, in the absence of other Axis I or II disorders on the Kiddie Schedule for Affective Disorders and Schizophrenia (K-SADS; Kaufman, Birmaher, Brent, Rao, \& Ryan, 1997). Exclusion criteria included: Prescription medication, illicit drug use, a history of head injury and an IQ $<70$ on the Wechsler Abbreviated Scale of Intelligence, vocabulary and matrix reasoning, (WASI; The Psychological Corporation., 1999). The mean age of the sample was 16.2 ( $S D=0.88$, range 13-18) years. All participants were British born with 96 (83\%) being Caucasian. The remainder of the sample were of Asian or Afro-Caribbean decent. The mean age at first arrest was 12.8 years (SD 1.7). The mean IQ of the sample was 86.13 ( $S D=9.1$, range $70-116$ ). Offences ranged from drug and acquisitive offences to homicide.

\subsection{Procedure and measures}

The study was approved by the North West Region Multicentre Ethics committee. Participants were tested as part of a larger study examining neuropsychological functioning in conduct disordered young offenders. All data was confidentially recorded and not accessible to custodial or professional staff.

\subsubsection{Thepsychopathy checklist youth version (PCL: YV; Forth, Kosson, E Hare, 2003)}

Psychopathic traits were assessed by trained researchers using the PCL:YV. Reliability checks for the overall study have been conducted on multiple occasions $(n=30)$. For this report 10 random cases were selected for this data and revealed Intraclass Correlation Coefficients for two raters on total scores of 0.96 , which were satisfactory in terms of our previous reports (Dolan \& Fullam, 2010) and for PCL: YV manual citations. The range of psychopathy scores for the sample was 2-37. As there are no agreed cross cultural cut-off scores for assignment into "psychopathic" and "nonpsychopathic" groups using the PCL: YV, we categorised our sample into high medium and low based on the 33rd and 66th percentile for PCL: YV total score to obtain 3 groups; Low Psychopathic traits (LP, $\leqslant 18, n=39$ ), Moderate Psychopathic traits (MP, 18-24, $n=31$ ) and High Psychopathic traits (HP > 24, $n=45$ ). This was chosen as the preferred method as it compares with our previous studies (e.g. Dolan \& Fullam, 2010) and overcomes concerns about arbitrary cut-off scores in many juvenile samples (Dolan, 2004).

\subsubsection{The child behaviour checklist (CBCL; Achenbach, 1991)}

The CBCL was assessed in the larger study but the delinquency and aggression scales (sample range: delinquency 0-23, aggression 0-37) are reported here given their relevance for comparative studies on the M/C task. The CBCL-118 item scale has excellent psychometric properties (Stevens, Vollebergh, Pels, \& Crijnen, 2005; Weisz, Sigman, Weiss, \& Mosk, 1993).

\subsubsection{The moral/conventional $(M / C)$ distinction task}

The eight stories ( 4 moral, 4 conventional) used to measure the $\mathrm{M} / \mathrm{C}$ distinction were identical to those cited in a previous study of adult psychopaths (Blair, 1995) and children with psychopathic traits (Blair et al., 2001). Participants were assessed individually by a rater who was blind to the participants' psychopathy scores. Participants were told that they would be asked some questions about events that sometimes happen in school. Each story was read out to the participants individually and the order of the task was randomised across participants. After the transgression scene

Table 1

Moral convention distinction task.

\begin{tabular}{|c|c|c|}
\hline $\begin{array}{l}\text { Moral stories } \\
\text { Conventional stories }\end{array}$ & \multicolumn{2}{|c|}{$\begin{array}{l}\text { (1) One child hitting another, (2) a child knocking another child over, (3) a child smashing the school piano and } \\
\text { (4) a child taking another's bag } \\
\text { (1) A boy wearing a skirt; (2) two children talking in class; (3) a child walking out of a classroom without } \\
\text { permission and (4) a child who turns his back on the teacher }\end{array}$} \\
\hline Question & Purpose & Scoring criteria \\
\hline NR Q1: “Is it ok to do (the transgression)?" & $\begin{array}{l}\text { Non-permissibility of } \\
\text { the act }\end{array}$ & $\begin{array}{l}\text { Yes }=0 ; \text { no }=1 \text {. Higher scores reflect more prohibitive judgements } \\
\text { Total score range } 0-4 \text {. Termed permissibility in Blair's (1995) (1997) earlier work }\end{array}$ \\
\hline $\begin{array}{l}\text { NR Q2: "How bad was it to do (the transgression)? } \\
\text { Scale of } 1-10 \text { with } 10 \text { being very bad }\end{array}$ & $\begin{array}{l}\text { Perceived seriousness } \\
\text { of the act }\end{array}$ & $\begin{array}{l}\text { Seriousness value }(1-10) \\
\text { Total possible score } 40 \text {. Higher scores }=\text { more serious }\end{array}$ \\
\hline NR Q3: "Why is it bad to do (the transgression)?" & $\begin{array}{l}\text { Subject's justifications } \\
\text { about the transgression }\end{array}$ & $\begin{array}{l}\text { Scored based on previous research (Smetana, 1995). Categorical scores; reference to } \\
\text { victim's welfare (e.g. 'It will hurt him') or to normative data (social responses e.g. 'It's } \\
\text { not acceptable to do that'). Scores across all } 4 \text { scenarios summed }\end{array}$ \\
\hline $\begin{array}{l}\text { MR Q4: "If the teacher in the school said that } \\
\text { anybody can do (the transgression) would this } \\
\text { be OK?" }\end{array}$ & $\begin{array}{l}\text { Non-permissibility } \\
\text { under authority } \\
\text { jurisdiction }\end{array}$ & $\begin{array}{l}\text { Yes }=0 ; \text { no }=1 . \text { Higher scores reflect more prohibitive judgements } \\
\text { Total score range } 0-4\end{array}$ \\
\hline
\end{tabular}

Note: $\mathrm{NR}=$ normal rule and $\mathrm{MD}=$ modified rule. 


\section{دريافت فورى ـ ـ متن كامل مقاله}

\section{ISIArticles}

مرجع مقالات تخصصى ايران

ل امكان دانلود نسخه تمام متن مقالات انكليسى ل امكان دانلود نسخه ترجمه شده مقالات ل يذيرش سفارش ترجمه تخصصى $\checkmark$ ل امكان جستجو در آرشيو جامعى از صدها موضوع و هزاران مقاله ل امكان دانلود رايكان r صفحه اول هر مقاله

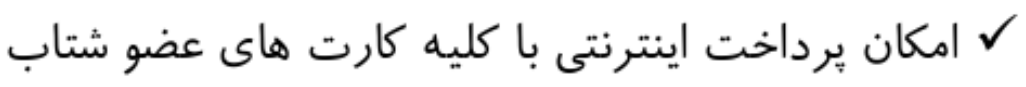
ل دانلود فورى مقاله پِ از برداخت آنلاين

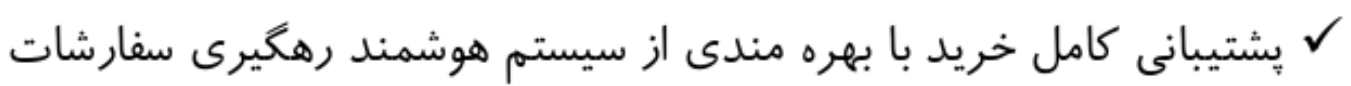

